\title{
The Stroke Unit Story: Where Have We Been and Where Are We Going?
}

\author{
Peter Langhorne \\ Institute of Cardiovascular and Medical Sciences, Academic Section of Geriatric Medicine, University of Glasgow, \\ Glasgow, UK
}

\section{Keywords}

Stroke unit · Outcome · Systematic review · Randomized trial

\begin{abstract}
Background: The concept of stroke unit care has been discussed for over 50 years, but it is only in the last 25 years that clear evidence of its effectiveness has emerged to inform these discussions. Summary: This review outlines the history of the concept of stroke units to improve recovery after stroke and their evaluation in clinical trials. It describes the first systematic review of stroke unit trials published in 1993, the establishment of a collaborative research group (the Stroke Unit Trialists' Collaboration), the subsequent analyses and updates of the evidence base, and the efforts to implement stroke unit care in routine settings. The final section considers some of the remaining challenges in this area of research and clinical practice. Key Messages: Good quality evidence confirms that stroke patients who are looked after in a stroke unit are more likely to survive and be independent and living at home 1 year after their stroke. The apparent benefits are independent of patient age, sex, stroke type, or initial stroke severity. The benefits are most obvious in units
\end{abstract}

karger@karger.com www.karger.com/ced

Karger $\stackrel{\text { ' }}{5}$
(C) 2021 The Author(s)

Published by S. Karger AG, Basel

This is an Open Access article licensed under the Creative Common Attribution-NonCommercial-4.0 International License (CC BY-NC) (http://www.karger.com/Services/OpenAccessLicense), applicable to the online version of the article only. Usage and distribution for commercial purposes requires written permission. based in a discrete ward (stroke ward). The current challenges include integrating effective stroke units with more recent systems to deliver hyper-acute stroke interventions and implementing stroke units in lower resource regions.

(c) 2021 The Author(s)

Published by S. Karger AG, Base

\section{Introduction}

During much of the 20th century, the medical profession in general held a nihilistic view about the treatment of stroke disease and the management of stroke patients. No clear effective medical interventions had been identified, and it was believed that little could be done to alter the natural history of the condition [1]. Indeed, there was once a view that stroke was an inevitable consequence of aging that would not respond to prevention or treatment strategies [2]. A further complicating factor was that across different countries, stroke patients were the responsibility of a range of different medical specialists (Neurology, General Medicine, Geriatric Medicine, and Rehabilitation Medicine), so there was no clear international consensus on how management should be approached [3]. Although several exceptional pioneers de- 
Table 1. Some key dates in the development of stroke unit care

\begin{tabular}{|c|c|}
\hline Date & Events \\
\hline $1950 \mathrm{~s}$ & Published descriptions of organized stroke care $[2,4]$ \\
\hline $1960 \mathrm{~s}$ & Published trials of organized stroke rehabilitation unit $[5,6]$ \\
\hline \multirow[t]{2}{*}{ 1970s } & Published descriptions of stroke intensive care units [7] \\
\hline & Development of the comprehensive (acute and rehabilitation) stroke unit [8] \\
\hline 1980 & First larger stroke unit trials [9] \\
\hline 1991 & First trial shows convincing benefit of stroke unit care [10] \\
\hline 1993 & First systematic review shows benefit of stroke unit care [13] \\
\hline 1997 & Updated systematic review shows convincing benefit of stroke unit care $[15,16]$ \\
\hline \multirow[t]{2}{*}{$2000 s$} & Multiple clinical practice guidelines begin to recommend establishing stroke units \\
\hline & Observational studies show improved outcomes associated with stroke unit care \\
\hline 2014 & World Stroke Organization guidelines recommend establishing stroke units [24] \\
\hline 2018 & International observational study confirms benefits associated with stroke unit care [39] \\
\hline 2020 & Latest update of the Cochrane stroke unit review [22] \\
\hline
\end{tabular}

The table outlines the chronological sequence of events that are described in the review.

veloped novel approaches to promote rehabilitation and recovery after stroke (see below), by 1990, there was no apparent agreement on the best strategies to manage stroke patients. Most of the current evidence-based stroke medicine interventions have been developed in the subsequent 30 years. This review will consider the history of this time period, in particular how the evidence for stroke unit care was compiled and disseminated. The discussion will conclude with discussion of the relevance of stroke units in modern stroke care.

\section{Stroke Unit Care}

The first descriptions of managing stroke patients within a stroke unit setting (Table 1) appeared in the 1950s and 1960s [2]. The concept was to focus stroke care around a multidisciplinary team of stroke specialists who operated out of a single discrete unit (stroke unit). Stroke units that focussed on the rehabilitation phase of the patient journey were described in Northern Ireland in the 1950s [4] and in the USA in the 1960s [5, 6]. By the 1970s, pioneers in North America [7] had begun to explore the impact of stroke intensive care units, while in Sweden, researchers developed a model of stroke unit which combined both acute care and early rehabilitation [8]. However, the first large trial (with $>300$ participants) did not appear until 1980 [9], and the first with convincing evidence of benefit was published in 1991 [10]. However, by the 1990s, there was no clear consensus on whether stroke units were worthwhile [3]. Inevitably, the geographical coverage of stroke units was very patchy.

The Stroke Unit Story

\section{Systematic Review of Stroke Unit Care}

My first involvement with the topic began in 1991 after exploring the literature on stroke units. Some articles questioned the cost-effectiveness of providing for stroke patients a complex package of care that included a range of different disciplines. While reading one of these articles, a fully formed question seemed to be presented, namely, how could we know that stroke units are effective? At this time, a new science of reviewing evidence (systematic review and meta-analysis) was being developed [11] although the Cochrane Collaboration had not yet become established [12]. It seemed clear that the first step to explore this question of stroke unit effectiveness should be to carry out a systematic review and meta-analysis providing that there were sufficient numbers of randomized trials. I subsequently learned that other researchers had considered this possibility but dismissed it as unrealistic because of the heterogeneous nature of the stroke unit intervention.

\section{First Stroke Unit Review}

We began work on the first iteration of the stroke unit review in 1991 using the standard systematic review approach available [11]. A key early step was to define the intervention in such a way that we could reliably select or exclude interventions that had been tested within clinical trials. Based on the existing descriptive literature, we chose to define a stroke unit as incorporating a "multidisciplinary team of specialists in the care of stroke pa- 


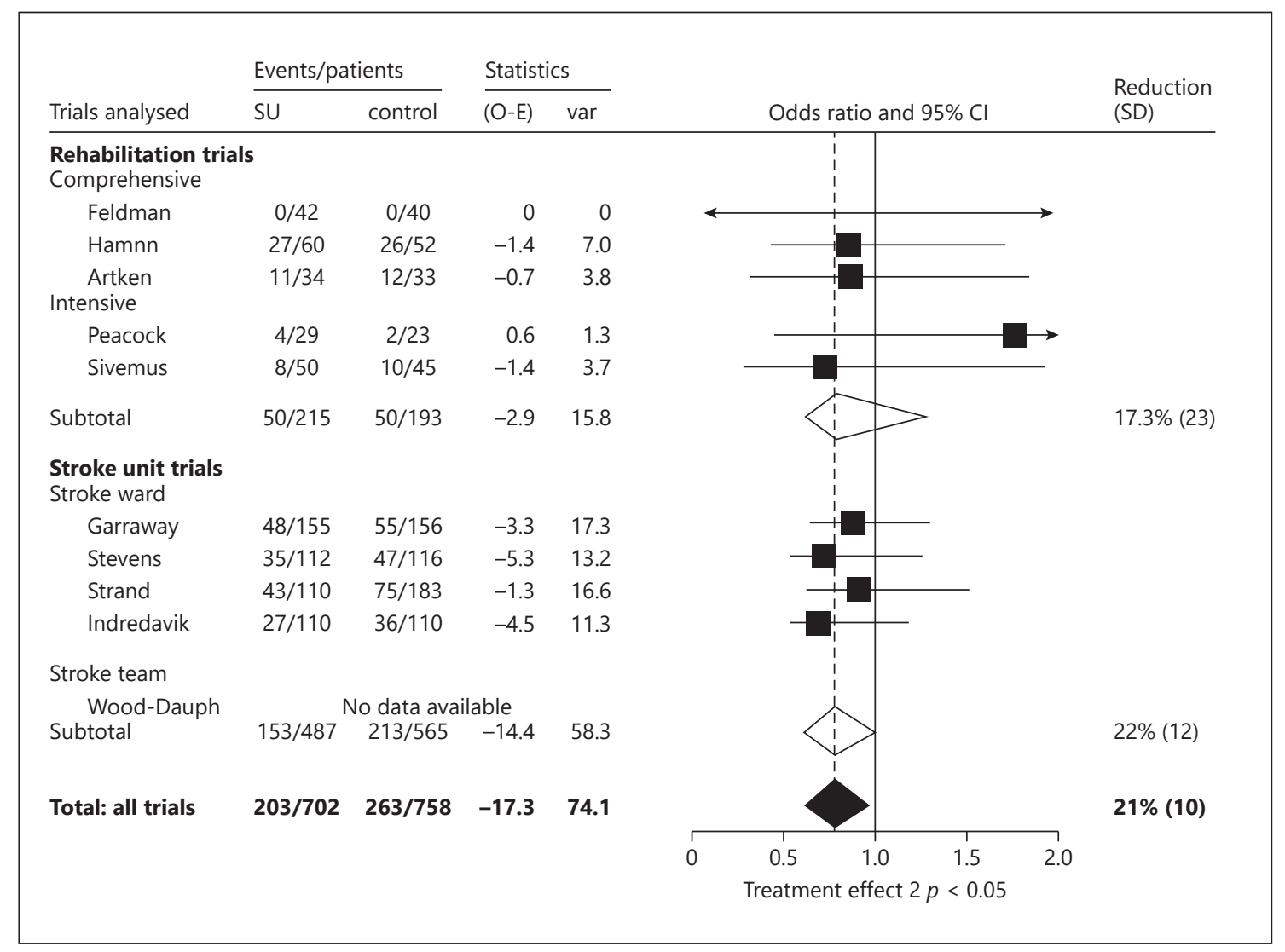

Fig. 1. First stroke unit review. The figure shows the reduction in deaths in SU versus general wards (control): recorded at 3-4 months after stroke. 0-E, observed minus expected number of deaths in the treatment (SU) group; var, variance; solid square, odds ratio of death in the SU group for each trial with its 95\% CI (horizontal line); diamond, overview of trial results and 95\% CI; SU, stroke unit. Broken vertical line is the average odds ratio for all available trials. Reproduced with permission from [13].

tients." This broad definition could apply to a geographically defined stroke unit (stroke ward) or a mobile stroke team.

Our initial searches identified 10 relevant randomized trials [13] which were stratified into 2 distinct ways of delivering the basic stroke unit intervention ("focussed stroke unit" which fulfilled the more common expectations of a stroke unit and a similar but more general multidisciplinary "rehabilitation service"). The only outcome data that were consistently available across all trials were death recorded early (in the first 4 months) or at approximately 1 year after stroke. To our surprise and considerable excitement, the trials strongly indicated that stroke patients were less likely to die if they were managed in an organized (stroke unit) setting than if they received conventional care in general medical or neurology wards (Fig. 1). At this stage, we were not fully aware of the potential impact of these observations, but in a prescient editorial [14], Professor Donnan pointed out the potential implications for stroke medicine if we could justify organizing care in a stroke unit based around a team of stroke specialists. While we were delighted with the progress of the initial systematic review, there was concern that we had simply demonstrated a potentially curious result and while many important questions were still outstanding. In particular, we were concerned about: (a) what exactly is stroke unit care, (b) how reliable was the primary outcome result, (c) was there any impact on a range of potentially important secondary outcomes, (d) how generalizable were the results to different patient groups and different ways of providing stroke unit care, and (e) how robust were the results when the ongoing trials were included in the near future. It was for these reasons that the Stroke Unit Trialists' Collaboration was established. 


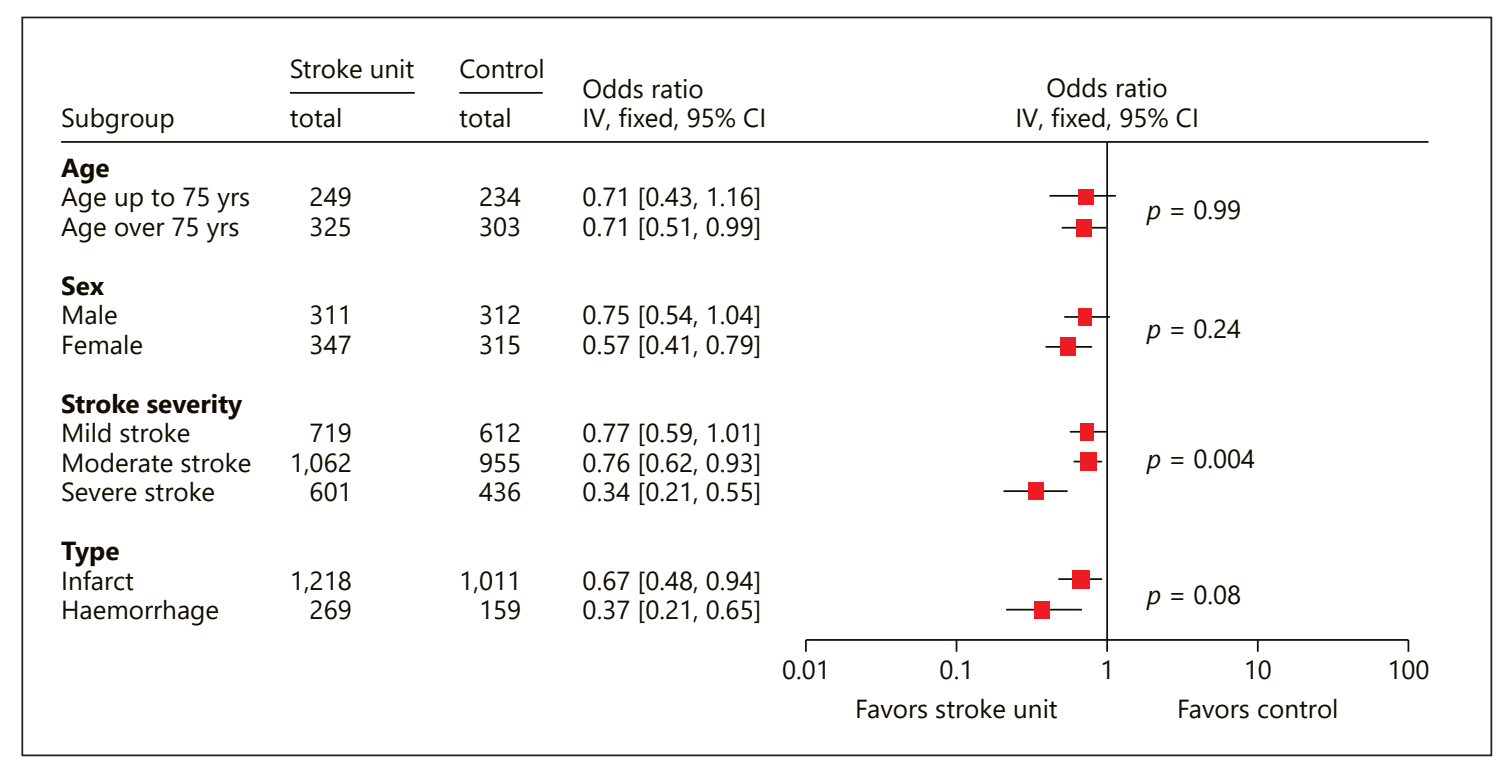

Fig. 2. Subgroup analysis by patient characteristics. The figure shows the subgroup analysis by patient characteristics where the outcome is shown as the odds ratio of a poor outcome (death or dependency or requiring institutional care) at the end of scheduled follow-up. Analyses used the generic inverse variance approach. $p$ values relate to the subgroup interaction. The analysis shows potential subgroup differences for stroke severity only. Reproduced with permission from [22].

\section{Stroke Unit Trialists' Collaboration}

The Stroke Unit Trialists' Collaboration was established using a modest grant from the charity Chest Heart and Stroke Scotland with the aim of optimizing the information available from the stroke unit trials and keeping the results up to date. The Principal Investigators of all the trials that fulfilled the inclusion criteria for the stroke unit review were contacted and invited to join a collaborative research group [15]. The trialists were asked to provide details about their trial design, selection criteria, patient characteristics, details of service organization (both stroke unit and comparison service), specific treatments delivered, numbers in each outcome group (and in selected subgroups), and additional services provided after discharge from the hospital. The survey of the trial characteristics included a structured interview to explore the structure, staffing, organization, procedures, and practices within the stroke unit and control group settings [15]. Key outcome data were provided at the end of scheduled follow-up plus additional information for various patient subgroups. After checking data accuracy and completing preliminary analyses, a trialists meeting was held in 1995 at which the results were shared and their implications discussed. This process resulted in 2 major publications in $1997[15,16]$ that aimed to address a num- ber of the remaining uncertainties about the nature and impact of stroke units.

- What is a stroke unit - we recognized that stroke units were complex interventions incorporating multiple interacting components. The semi-structured interviews and subsequent service description and discussion helped to provide more detail about the nature of stroke unit care [2,15-17]. We learned that within the clinical trials, a stroke unit typically (a) incorporated staff with a specialist interest in stroke and/or rehabilitation and (b) provided a coordinated multidisciplinary rehabilitation package with (c) staff training and education and (d) protocols for managing standard problems and challenges. Most teams met at least once a week to plan the care of individual patients. Although this broad definition could include peripatetic stroke teams (mobile stroke team), most of the evidence came from services where the team was located in a discrete hospital ward (stroke ward).

- Primary outcomes - the initial systematic review [13] included 10 trials (1,586 participants) and had considerable uncertainty around the precision of the primary outcome estimate. The first updated collaborative review [15] included 19 trials (3,249 participants) and confirmed that patients who were managed in a stroke unit setting and followed up for 6 months to 1 year were 
less likely to have died, be physically dependent, or to require institutional care than those managed in conventional care in general medical or neurology wards. The observed benefits were not diminished by focussing only on the most methodologically robust trials.

- Secondary outcomes - the updated review $[15,16]$ sought information about a range of secondary outcomes although often information was limited. However, it did demonstrate that there was no systematic increase in length of stay and no adverse effect on patient mood or carer outcomes. Two trials subsequently suggested an improvement in quality of life [18], but very few data were available. The 3 trials which followed up patients for 5 or 10 years [18] indicated that the benefits were sustained over the long term. A reduction in post-stroke complications [19] seemed to provide part of the explanation for the benefits of stroke unit care.

- Subgroup analysis - in the collaborative review [15, 16], we sought subgroup information about patient age, sex, baseline stroke severity, and stroke type. We also carried out subgroup analyses by different approaches to delivering stroke unit care. These analyses indicated that the apparent benefits of stroke unit care were not restricted to any subgroup of stroke patients or particular model of stroke unit care (Fig. 2). However, patients with more severe stroke at baseline were more likely to benefit by avoiding death or institutional care, whereas those with milder stroke were more likely to avoid long-term disability $[16,18]$. Similar benefits were seen with cerebral infarct and haemorrhage [20]. The departmental setting of the unit did not seem to influence effectiveness providing that the stroke unit model of care could be provided for as long as it was required [15]. As regards the different models of stroke unit care $[18,21,22]$, most of the evidence comes from stroke teams housed within a geographically discrete ward (stroke ward).

- Updating the evidence - at the time of establishing the Stroke Unit Trialists' Collaboration, we became aware of several ongoing randomized trials in different countries which had the potential to substantially influence the estimates of effect of stroke unit care. To ensure an up-to-date evidence base, these newer trials were added to the Cochrane Library version of the stroke unit review with updates taking place in 2001, 2007, 2013, and most recently 2020 [22]. The latest version of the review now includes 29 trials (5,902 participants) that compared organized inpatient stroke unit care with an alternative service. This update further categorized the types of stroke unit service and conducted a network meta-analysis to explore the effectiveness of different models of stroke unit care. The conclusion in 2020 remains that we have moderate-quality evidence that stroke patients who receive stroke unit care are more likely to be alive, independent, and living at home 1 year after their stroke. The apparent benefits remain independent of patient age, sex, initial stroke severity, or stroke type. The benefits were most obvious in units based in a discrete ward (stroke ward).

\section{Implementation of Stroke Unit Care}

The collaborative review group initially had representation from 7 , rising to 12 different countries. One unanticipated benefit of establishing such an international group was that many of these individuals became champions of stroke unit care in their home countries, ensuring recognition in clinical practice guidelines and in national efforts to implement stroke units. This resulted in recommendations in many national and regional clinical practice guidelines [23-26] that all stroke patients should be managed in a stroke unit. The degree to which different countries have succeeded in establishing stroke units is more variable, but they have become the norm of stroke care in most Scandinavian countries, the UK, several continental European countries, Australia, and Canada [26, 27].

One of the most exciting aspects of the implementation of stroke units has been not only that this has been possible but also that it has been associated with measurable improvements in patient outcomes. National register studies from Canada [28], Sweden [29], the UK [30], and Australia [31] plus some transnational studies [32, 33] have shown an association of access to care in a stroke unit in routine care settings with improved patient outcomes. Furthermore, the scale of benefit is very close to that reported in the clinical trials.

\section{Remaining Challenges}

Despite the recent success in rolling out stroke unit care, there remain some major areas of challenge and uncertainty.

Components of stroke unit care - although the complex package of stroke unit care appears to improve stroke recovery, the impact of many individual components remains unclear. Several trials of putative components have been disappointing or inconclusive including early mobilization [34], patient positioning [35], glucose manage- 
ment [36], and aggressive infection management [37]. Much more research is needed to understand the potential benefit of common interventions such as physiological monitoring, early mobilization strategies, routine dysphagia management, and rehabilitation at the transition home. The international AVERT-DOSE trial is currently underway (ACTRN12619000557134).

Stroke units in low-income settings - in theory, it appears to be feasible to run stroke units in low- and middleincome settings [38] but in practice may be difficult to achieve without supporting factors being in place. Many patients do not gain admission to a hospital, and even if they do, some of the basic components of healthcare services (adequate staffing, equipment, and infrastructure) are often not available in poorer settings. However, despite these challenges, a recent observational study [39] carried out in 108 hospitals across 28 different countries has indicated that recovery after stroke was improved if the hospital had a stroke unit established even within lowor middle-income countries (Fig. 3). The major challenge now concerns how do we establish and maintain stroke units in those poor-resource settings that have not yet been able to develop such services. A number of research initiatives are underway $[40,41]$ to try and enhance staff training and staffing and to provide low-cost protocols of care that can be implemented much more widely.

Stroke units in high-income countries - when the first stroke units were developed, there was no proven medical or surgical intervention for ischaemic or haemorrhagic stroke. Since then, a number of interventions have been developed particularly for very early reperfusion in proximal vessel ischaemic stroke [42]. As a result, many services are being re-shaped with the explicit aim of providing emergency thrombolysis and/or thrombectomy [43]. This has resulted in the development of service models (such as comprehensive stroke centres and primary stroke centres) where the primary focus is on delivering hyperacute interventions rather than on delivering the stroke unit model of care $[43,44]$. For example, the "mobile stroke unit" model $[45,46]$ aims to deliver rapid investigation and medical treatment but not to provide any more conventional aspects of stroke unit care described in the stroke unit trials. An additional challenge is that many hyper-acute services (neuroradiology and neurosurgery) to which patients are being re-directed are expert in delivering instrumental treatments such as thrombectomy or decompressive surgery but do not have a tradition of providing stroke unit care for elderly stroke patients.

While these developments make planning patient care more complex, it should be possible to match the clinical

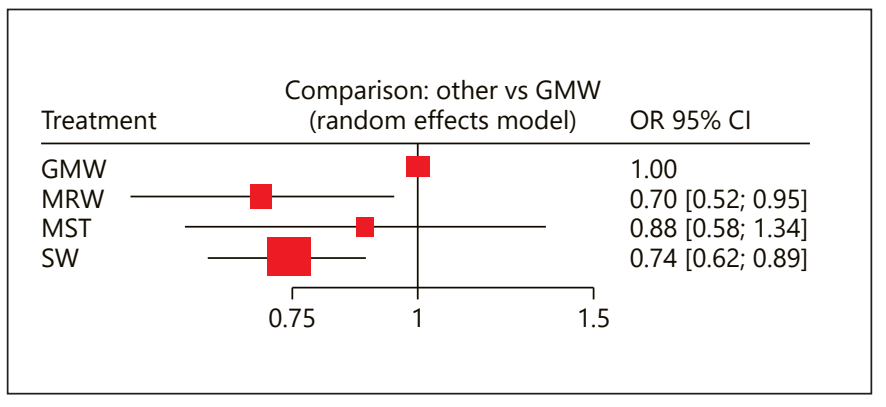

Fig. 3. Network meta-analysis by stroke unit type. The network meta-analysis plot shows different types or organized care. The outcome is a poor outcome (death or dependency or requiring institutional care) at the end of scheduled follow-up. The treatment column shows the service groups (MRW, MST, and SW) versus GMW. The results are the odds ratio (95\% confidence interval) of a poor outcome, with care in a GMW as the reference $(\mathrm{OR}=1.0)$. Reproduced with permission from [22]. MRW, mixed rehabilitation ward; MST, mobile stroke team; SW, stroke ward; GMW, general medical ward.

services to the needs of the patient [42]. This requires a focus on the best timing of the most appropriate care for the individual patient. First, the modern reperfusion strategies almost exclusively operate in the first few hours after stroke, whereas the stroke unit approach focusses on the early days and weeks after stroke. Second, the majority of stroke patients are not eligible for hyper-acute reperfusion therapies [42] but can still benefit from expert care in a stroke unit. Third, many patients who respond well to reperfusion will still have persisting impairment and disability [42] and will require coordinated multidisciplinary stroke unit care.

The solution appears to be to focus on the most appropriate patient journey for an individual patient such that every patient gets the best available care most relevant to the needs at the correct time. For a substantial minority of the stroke patient population, this will include a hyperacute reperfusion strategy with a thrombolytic drug and/ or mechanical thrombectomy. However, most will subsequently require skilled nursing, physiological management, prevention of complications, early rehabilitation, and multidisciplinary patient care with subsequent discharge planning and possibly ongoing rehabilitation after returning home.

\section{Conclusion}

The basic concept of stroke unit care has been debated for over 50 years, but it is only in the last 25 years that the potential benefits have been recognized. In many coun- 
tries, this has meant not only the improvement of patient care within stroke units but also provided the focus for stroke "champions" to plan and develop other improvements in the stroke patient journey. These additional benefits of establishing stroke units have undoubtedly promoted a better patient care, a better focus for patient and carers' needs, and a better focus for clinical stroke research. The challenges of the more modern "reperfusion revolution" are how to provide the high technology services required for those who will benefit from reperfusion strategies without dismantling the established and highly effective stroke unit pathways. The solution would appear to be to focus on the ideal patient journey to ensure that every patient gets the best available care for his/ her needs. For many, this will include a hyper-acute reperfusion strategy but most will also subsequently require the stroke unit package of skilled nursing, physiological management, prevention of complications, early rehabilitation, and multidisciplinary patient care. Both approaches should be complementary and should be able to operate together to further improve stroke patient care.

\section{Acknowledgments}

The author wants to thank the Stroke Unit Trialists' Collaboration who inspired and supported much of the research described here and Chest Heart and Stroke Scotland who funded the main project. This study was published in celebration of the 30th anniversary of the inception of Cerebrovascular Diseases 1991-2021.

\section{Conflict of Interest Statement}

The author has no conflicts of interest to declare.

\section{Funding Sources}

The medical charity Chest Heart and Stroke Scotland funded the main project.

\section{References}

1 Weatherall DJ, Ledingham JGG, Warrell DA. Oxford textbook of medicine (2 Volumes). Oxford, UK: Oxford University Press; 1983.

2 Langhorne P, Dennis MS. Stroke units : an evidence-based approach. London: BMJ Publishing; 1998.

3 Ebrahim S. Clinical epidemiology of stroke. Oxford: Oxford University Press (Medical Publications); 1990.

4 Adams GF. Prognosis and prospect of strokes. In: Cerebrovascular disability and the ageing brain. Edinburgh: Churchill Livingstone; 1974.

5 Feldman DJ, Lee PR, Unterecker J, Lloyd K, Rusk HA, Toole A. A comparison of functionally orientated medical care and formal rehabilitation in the management of patients with hemiplegia due to cerebrovascular disease. J Chronic Dis. 1962;15:297-310.

6 Gordon EE, Kohn KH. Evaluation of rehabilitation methods in the hemiplegic patient. J Chronic Dis. 1966;19:3.

7 Millikan CH. Stroke intensive care units: objectives and results. Adv Neurol. 1979;25: 361-5.

8 Strand T, Asplund K, Eriksson S, Hägg E, Lithner F, Wester PO. A non-intensive stroke unit reduces functional disability and the need for long-term hospitalization. Stroke. 1985;16:29-34.

9 Garraway WM, Akhtar AJ, Prescott RJ, Hockey L. Management of acute stroke in the elderly: preliminary results of a controlled trial. Br Med J. 1980;280:1040-3.
10 Indredavik B, Bakke F, Solberg R, Rokseth R, Haahein LL, Home I. Benefit of stroke unit: a randomised controlled trial. Stroke. 1991;22: 1026-31.

11 Peto R. Why do we need systematic overviews of randomized trials? Stat Med. 1987;6:233-44.

12 Sandercock P, Warlow C, Counsell C, Fraser $\mathrm{H}$; Cochrane Collaboration Stroke Review Group. Systematic reviews of treatments relevant to stroke patients: the Cochrane Collaboration. Cerebrovascular Dis. 1994;4:248.

13 Langhorne P, Williams BO, Gilchrist W, Howie K. Do stroke units save lives? Lancet. 1993;342:395-8.

14 Donnan GA. Lifesaving for stroke. Lancet. 1993;342:383-4.

15 Stroke Unit Trialists' Collaboration. Collaborative systematic review of the randomised trials of organised inpatient (stroke unit) care after stroke. BMJ. 1997;314:1151-9.

16 Stroke Unit Trialists' Collaboration. How do stroke units improve patient outcomes? A collaborative systematic review of the randomised trials. Stroke. 1997;28:2139-44.

17 Langhorne P, Pollock A; Conjunction with the Stroke Unit Trialists' Collaboration. What are the components of effective stroke unit care? Age Ageing. 2002;31:365-71.

18 Stroke Unit Trialists' Collaboration. Organised inpatient (stroke unit) care for stroke. Cochrane Database Syst Rev. 2013;9:CD000197.

19 Govan L, Langhorne P, Weir CJ; Stroke Unit Trialists Collaboration. Does the prevention of complications explain the survival benefit of organised inpatient (stroke unit) care? Further analysis of a systematic review. Stroke. 2007;38:2536-40.

20 Langhorne P, Fearon P, Ronning OM, Kaste M, Palomaki H, Vemmos K, et al. Stroke unit care benefits patients with intracerebral hemorrhage: systematic review and meta-analysis. Stroke. 2013;44:3044-9.

21 Langhorne P, Dey P, Woodman M, Kalra L, Wood-Dauphinee S, Patel N, et al. Is stroke unit care portable? A systematic review of the clinical trials. Age Ageing. 2005;34:324-30.

22 Langhorne P, Ramachandra S; Stroke Unit Trialists' Collaboration. Organised inpatient (stroke unit) care for stroke: network meta analysis. Cochrane Database Sys Rev. 2020;4. CD000197.

23 Stroke Foundation. Clinical Guidelines for Stroke Management - Chapter 3 of 8: acute medical and surgical management (v8.0 published); 2020. Available from: https://app. magicapp.org/\#/guideline/3971.

24 Lindsay P, Furie KL, Davis SM, Donnan GA, Norrving B. World stroke organization global stroke services guidelines and action plan. Int J Stroke. 2014 Oct;9(Suppl A100):4-13.

25 National Collaborating Centre for Chronic Conditions; National Institute for Health and Care Excellence (Commissioner). National clinical guideline for diagnosis and initial management of acute stroke and transient ischaemic attack (TIA) (NICE NG128). London: Royal College of Physicians; 2019. Available from: https://www.nice.org.uk/guidance/ng128. 
26 Norrving B, Barrick J, Davalos A, Dichgans $\mathrm{M}$, Cordonnier C, Guekht A, et al. Action Plan for Stroke in Europe 2018-2030. Eur Stroke J. 2018;3(4):309-36.

27 Cadilhac DA, Andrew NE, Lannin NA, Middleton S, Levi CR, Dewey HM, et al. Quality of acute care and long-term quality of life and survival: the Australian stroke clinical registry. Stroke. 2017;48(4):1026-32.

28 Saposnik G, Hassan KA, Selchen D, Fang J, Kapral MK, Smith EE. Investigators of the registry of the Canadian stroke network for the stroke outcome research Canada (SORCan) working group. Stroke unit care: does ischemic stroke subtype matter? Int J Stroke. 2011 Jun;6(3):244-50. http://www.sorcan.ca.

29 Asplund K, Hulter-Asberg K, Norrving B, Stegmayr B, Terént A, Wester PO, et al. Riks-Stroke a Swedish national quality register for stroke care. Cerebrovasc Dis. 2003;15(Suppl 1):5-7.

30 Morris S, Ramsay AIG, Boaden RJ, Hunter RM, McKevitt C, Paley L, et al. Impact and sustainability of centralising acute stroke services in English metropolitan areas: retrospective analysis of hospital episode statistics and stroke national audit data. BMJ. 2019;364:11.

31 Busingye D, Kilkenny MF, Purvis T, Kim J, Middleton S, Campbell BCV, et al. Is length of time in a stroke unit associated with better outcomes for patients with stroke in Australia? An observational study. BMJ Open. 2018; 8:e022536.

32 Seenan P, Long M, Langhorne P. Stroke units in their natural habitat: a systematic review of observational studies. Stroke. 2007;38:188692.
33 Urimubenshi G, Langhorne P, Cadilhac DA, Kagwiza JN, Wu O. Association between patient outcomes and key performance indicators of stroke care quality: a systematic review and meta-analysis. Eur Stroke J. 2017;2:287307.

34 AVERT Trial Collaboration Group. Efficacy and safety of very early mobilisation within 24 $\mathrm{h}$ of stroke onset (AVERT): a randomised controlled trial. Lancet. 2015;386(9988):4655.

35 Anderson CS, Arima H, Lavados P, Billot L, Hackett ML, Olavarría VV, et al. Cluster-randomized, crossover trial of head positioning in acute stroke. N Engl J Med. 2017;376(25): 2437-47.

36 Middleton S, McElduff P, Ward J, Grimshaw JM, Dale S, D’Este C, et al. Implementation of evidence-based treatment protocols to manage fever, hyperglycaemia, and swallowing dysfunction in acute stroke (QASC): a cluster randomised controlled trial. Lancet. 2011 Nov 12;378(9804):1699-706.

37 Vermeij JD, Westendorp WF, Dippel DW, van de Beek D, Nederkoorn PJ. Antibiotic therapy for preventing infections in people with acute stroke. Cochrane Database Syst Rev. 2018;1:CD008530.

38 Langhorne P, de Villiers L, Pandian JD. Applicability of stroke-unit care to low-income and middle-income countries. Lancet Neurol. 2012;11:341-8.
39 Langhorne P, O’Donnell MJ, Chin SL, Zhang $\mathrm{H}$, Xavier D, Avezum A, et al. Practice patterns and outcomes after stroke across countries at different economic levels (INTERSTROKE): an international observational study. Lancet. 2018;391(10134):2019-27.

40 Pandian JD, Kalkonde Y, Sebastian IA, Felix C, Urimubenshi G, Bosch J. Stroke systems of care in low-income and middle-income countries: challenges and opportunities. Lancet. 2020;396:1443-51.

41 Lindley RI. Providing stroke expertise across India. J Neurosci Rural Pract. 2021;12(2):226-7.

42 Langhorne P, Audebert HJ, Cadilhac DA, Kim J, Lindsay P. Stroke systems of care in high-income countries: what is optimal? Lancet. 2020 Oct 31;396(10260):1433-42.

43 Ringelstein EB, Chamorro A, Kaste M, Langhorne P, Leys D, Lyrer P, et al. European Stroke Organisation (ESO) recommendations to establish a stroke unit and stroke centre. Stroke. 2013;44(3):828-40.

44 Man S, Zhao X, Uchino K, Hussain MS, Smith $\mathrm{EE}$, Bhatt DL, et al. Comparison of acute ischemic stroke care and outcomes between comprehensive stroke centers and primary stroke centers in the United States. Circ Cardiovasc Qual Outcomes. 2018 Jun;11(6):e004512.

45 Fassbender K, Grotta JC, Walter S, Grunwald IQ, Ragoschke-Schumm A, Saver JL. Mobile stroke units for prehospital thrombolysis, triage, and beyond: benefits and challenges. Lancet Neurol. 2017;16(3):227-37.

46 Calderon VJ, Kasturiarachi BM, Lin E, Bansal $\mathrm{V}$, Zaidat OO. Review of the mobile stroke unit experience worldwide. Interv Neurol. 2018;7(6):347-58. 